\title{
Antibiogram of Escherichia coli and Pseudomonas Strains Isolated from Wastewater Generated by an Abattoir as It Journeys into a Receiving River
}

\author{
Olutayo I. Falodun, Abimbola O. Adekanmbi* \\ Environmental Microbiology and Biotechnology Laboratory, Department of Microbiology, University of Ibadan, \\ Ibadan, Nigeria \\ Email: "bimboleen@yahoo.com
}

Received 29 January 2016; accepted 16 April 2016; published 19 April 2016

Copyright (C) 2016 by authors and Scientific Research Publishing Inc.

This work is licensed under the Creative Commons Attribution International License (CC BY).

http://creativecommons.org/licenses/by/4.0/

(c) (i) Open Access

\begin{abstract}
Untreated wastewater from abattoir operations contains nutrients and other components that aid the growth of microorganisms especially bacteria. They also serve as a habitat for potentially pathogenic bacteria which might be a source of public health concern. The study was carried out to determine the antibiotics susceptibility profile of Gram-negative bacteria (Pseudomonas and Escherichia coli) to selected antibiotics. Wastewater samples were collected from ten different sampling points and cultured on Eosin Methylene Blue (EMB) and King's B medium. The bacterial strains obtained from the wastewater samples were subjected to antibiotics susceptibility tests, using the disc diffusion technique. A total of 60 Pseudomonas and 100 Escherichia coli were isolated out of which none of the Pseudomonas strains showed resistance to imipenem, colistin sulphate, meropenem and aztreonam, while $100 \%$ resistance was observed to ceftazidime and piperacillin. All the Escherichia coli strains were resistant to oxacillin and ceftazidime, while the percentage resistance to aztreonam, ertapenem, cefoxitin and tetracyline was $6 \%, 11 \%, 43 \%$ and $58 \%$ respectively. Eighty-five percent $(85 \%)$ of the total Escherichia coli showed resistance to more than two antibiotics, while $14 \%$ showed resistance to ceftazidime and oxacillin, with only one isolate showing resistance to ceftazidime and cefoxitin. There is the need for an effective treatment of wastewater generated from abattoir operations to prevent the potential spread and transmission of antibiotic resistant bacteria to the human population who depends heavily on some of the water bodies, receiving input from abattoir wastes.
\end{abstract}

\section{Keywords}

Abattoir, Pseudomonas Sp., Escherichia coli, Multidrug Resistance, Antibiotics

\footnotetext{
"Corresponding author.
}

How to cite this paper: Falodun, O.I. and Adekanmbi, A.O. (2016) Antibiogram of Escherichia coli and Pseudomonas Strains Isolated from Wastewater Generated by an Abattoir as It Journeys into a Receiving River. Advances in Microbiology, 6, 303-309. http://dx.doi.org/10.4236/aim.2016.64029 


\section{Introduction}

Abattoir effluents are wastewater generated from the slaughtering activities of animals in the abattoirs and usually consist of intestinal contents like blood and water [1]. Although operations in the abattoirs are of benefits to man in the provision of meat for human consumption, it can be hazardous to public health with respect to the untreated generated wastes which are discharged into the environment [2]. Like many other sewage types, effluents from the abattoir flow into water bodies such as ground water, streams, rivers, lakes and oceans thereby introducing enteric pathogens, excess nutrients and other contaminants into the water sources [3] [4]. The abattoir effluents released without treatment feed natural bodies of water with nutrients and the monitoring of the bacterial status of such effluents are of public health importance [5] [6] especially in Nigeria, a country where abattoir effluents like most other wastewater are untreated before they are discharged [1] [7].

The detection of pathogenic organisms as well as the incidence of proteolytic and lipolytic bacteria in a water body is suggestive of impending health hazards and public health concern [8]. Micronutrients in abattoir wastewater sustain the prevalence of pathogenic and entropic organisms that constitute biohazards in water bodies [8] [9]. The risk becomes high when the enteric pathogens which are present in the water bodies are resistant to antibiotics; this is because, if such bacteria cause infection, they will be very difficult to treat [10]. Furthermore, there could be transmission of antimicrobial resistance to autochthonous bacteria from faecal bacteria through lateral transfer, when the resistance genes are carried by transferable and mobile genetic elements such as plasmids; thus contributing to antimicrobial resistance multiplication and the spread in the environment [11]. Gramnegative infections include those caused by Klebsiella, Acinetobacter, Pseudomonas aeruginosa and E. coli as well as many other less common bacteria.

Pseudomonas species are gram-negative aerobic bacilli widely distributed in the natural environment and particularly abundant in soils and water; they are opportunistic and ubiquitous pathogens, probably due to their limited nutritional requirements and tolerance of adverse physical and chemical conditions [12]. Pseudomonas species show a wide continuum of resistance to different classes of antimicrobials agents and one of the principal factors linked to the emergence of microbial resistance is the abusive and indiscriminate use of antimicrobial agents [13]. The emergence of Pseudomonas strains with variable and growing levels of antimicrobial resistance has generated considerable health concern. E. coli is a common inhabitant of human and animal intestinal tract. It is a gram-negative facultative aerobic organism and the most common in the family Enterobacteriaceae. E. coli is also one of the standard indicator organisms for faecal pollution in environmental water [14]. Animal faeces can also contain pathogens like E. coli $\mathrm{O} 157$ and Salmonella species which can cause infection in humans [15]. This study was designed to determine the presence of gram-negative bacteria (Pseudomonas species and Escherichia coli) at different points from the flow of abattoir effluents in Bodija market in Ibadan North Local Government Area of Oyo State into a receiving river as well as determine their susceptibility to selected antibiotics.

\section{Materials and Methods}

\subsection{Study Site}

The study site was the Bodija abattoir located in Ibadan North Local Government Area of Oyo state, Nigeria. The descriptions of the sampling points and the Geographical Positioning System (GPS) readings have earlier been reported by Adekanmbi and Falodun [16].

\subsection{Sample Collection}

Wastewater samples from the Bodija abattoir were collected at different points as it flows via a drainage channel into a nearby receiving river. The samples were transported to the laboratory for microbiological analysis.

\subsection{Isolation and Characterization of Pseudomonas $\mathrm{Sp}$.}

Serial dilutions were carried out on the wastewater samples and $1 \mathrm{ml}$ of the appropriate dilution was plated out on King's B medium, using the standard pour plate technique of Harrigan and MacCance [17]. The plates were incubated at $35^{\circ} \mathrm{C}$ for five-seven days for growth to occur. Colonies showing visible greenish-yellow colouration (due to pigment production) were selected and further sub-cultured to obtain pure cultures. 


\subsection{Isolation of Escherichia coli}

One $\mathrm{ml}$ aliquot of the appropriate dilutions was plated out on Eosin Methylene Blue (EMB) agar using the pour plate technique. The plates were incubated at $35^{\circ} \mathrm{C}-37^{\circ} \mathrm{C}$ for 24 hours and growth observed. Colonies showing the green metallic sheen typical of Escherichia coli were selected and sub-cultured to obtain pure cultures.

\subsection{Characterization of the Bacterial Isolates}

The bacterial isolates (Pseudomonas sp. and Escherichia coli) were characterized using morphological, biochemical and sugar fermentation tests and compared with the scheme of Sneath [18].

\subsection{Antibiotic Susceptibility Test}

Antibiotic susceptibility test for the Gram negative isolates was carried out using the disc diffusion technique. The antibiotics were selected based on the CLSI [19] standards and they included: imipenem (10 $\mu \mathrm{g})$, aztreonam $(10 \mu \mathrm{g}$ and $30 \mu \mathrm{g})$, ceftazidime $(30 \mu \mathrm{g})$, colistin sulphate $(10 \mu \mathrm{g})$, piperacillin $(30 \mu \mathrm{g})$, meropenem $(10 \mu \mathrm{g})$, tetracycline $(30 \mu \mathrm{g})$, cefoxitin $(30 \mu \mathrm{g})$, and oxacillin $(1 \mu \mathrm{g})$. All the antibiotic discs were purchased from Oxoid, UK. The bacterial were seeded onto Mueller Hinton agar plates by picking an overnight $18-24$ hour culture of the isolates with an inoculating loop and suspended in a tube containing $0.85 \%$ saline. The turbidity was adjusted to $0.5 \mathrm{McF}$ arland standards. The suspension was spread uniformly over the already prepared Muller Hinton agar plate using sterile swab stick, and antibiotics were placed on the plates with the aid of sterile forceps. The plates were inverted and incubated at $35^{\circ} \mathrm{C}-37^{\circ} \mathrm{C}$ for $18-24$ hours. Zones of inhibition were measured after the incubation period and recorded. The values were compared with the CLSI [19] standards.

\section{Results}

A total of sixty (60) Pseudomonas species and one hundred (100) Escherichia coli were isolated from the waste water samples over the sampling duration. The percentage resistance of the isolated Gram negative strains is shown in Figure 1 and Figure 2. There was 100\% resistance to ceftazidime and piperacillin by the Pseudomonas strains, while there was no observed resistance to imipenem, meropenem, colistin sulphate and aztreonam. On the other hand, all (100\%) the Escherichia coli were resistant to oxacillin and ceftazidime, while the resistance to aztreonam, ertapenem, tetracycline and cefoxitin was $6 \%, 11 \%, 58 \%$ and $43 \%$ respectively.

The phenotypic pattern of resistance of the isolates is shown in Table 1 and Table 2. All the Pseudomonas strains showed the same pattern of resistance to the antibiotics (CAZ, PRL); while the Escherichia coli strains had different patterns of resistance to the six antibiotics tested against them. The highest frequency was 28 strains, showing resistance to CAZ, TE, OX; while 24 strains showed resistance to CAZ, TE, FOX, OX. In all, $38 \%$ of the Escherichia coli showed resistance to more than three antibiotics.

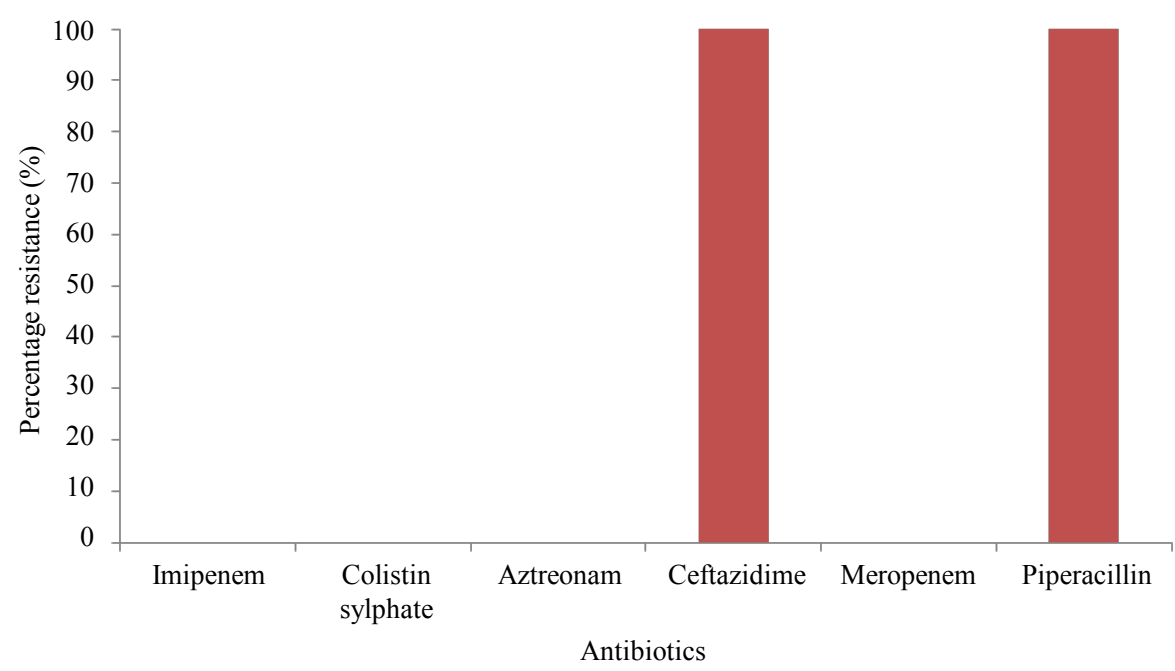

Figure 1. Percentage resistance of the Pseudomonas strains to the tested antibiotics. 


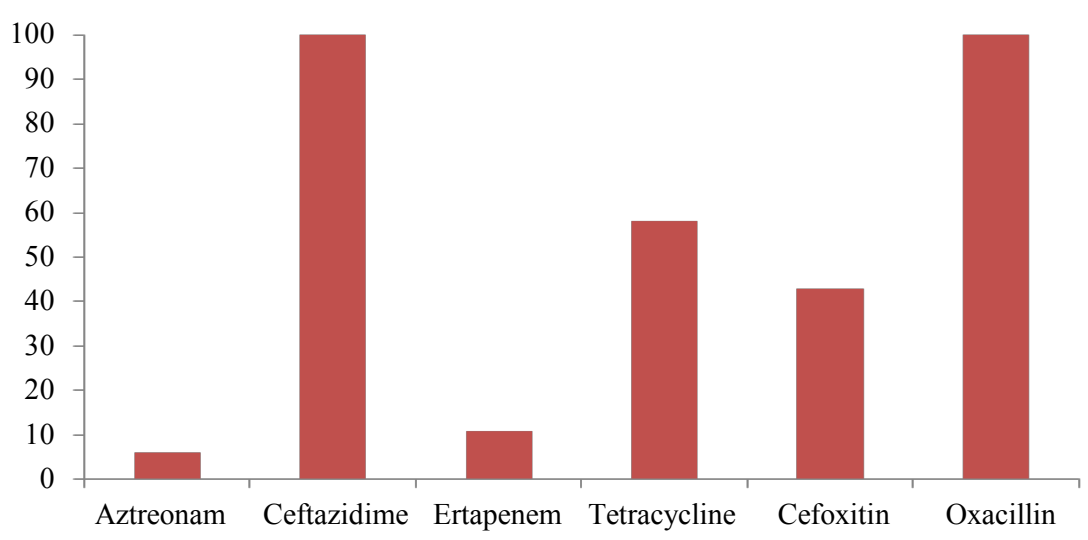

Figure 2. Percentage resistance of the Escherichia coli to the tested antibiotics.

\section{Discussion}

The isolation of Escherichia coli and Pseudomonas species from the Bodija, Ibadan abattoir further substantiates the fact that these Gram negative bacteria are associated with abattoir effluents as they have been previously isolated from abattoir wastewater in Nigeria [7] [20]-[22] and elsewhere [12] The observed resistance patterns of Pseudomonas strains in this study differs from the observation of Igbinosa et al. [20] regarding resistance to imipenem, aztreonam and meropenem. All the isolates in this study showed no resistance to the antibiotics whereas Igbinosa and his colleagues reported varying level of resistance to the drugs. However, resistance to ceftazidime and piperacillin $(100 \%)$ as observed in this study was higher than the $80 \%$ and $71.4 \%$ resistance reported by the same authors to the two antibiotics respectively. The noticed disparity may be due to the nature of the wastewater studied. Igbinosa and colleagues collected their samples prior to discharge into the receiving water body as against the samples from this study that were already discharged before sampling.

Moreover, the observation from this study was similar to a study carried out in a swine slaughterhouse in Brazil [12]. As observed in this study, all the Pseudomonas strains were completely resistant to imipenem and aztreonam. However, only $2.9 \%$ of the total strains in their study were reported to be resistant to meropenem while there was no resistance by the Pseudomonas strains in this study to the same antibiotic. Furthermore, all the isolates in this present study exhibited complete resistance to piperacillin and ceftazidime while Kelly et al. [12] reported that $100 \%$ and $91.2 \%$ of their Pseudomonas strains were resistant to the respective drugs. Similarly, both studies observed that the Pseudomonas isolates did not exhibit multi-resistance to the antimicrobials tested. The resistance obtained for imipenem (0\%), ceftazidime (100\%) and piperacillin (100\%) against the Pseudomonas strains is not in agreement with the $18 \%$ (imipenem), $34 \%$ (piperacillin) and $36 \%$ (ceftazidime) reported from another study in India [23]. In addition, the result of the resistance pattern of the Pseudomonas sp. to colistin sulphate and piperacillin were similar to a previous report on wastewater and wastewater impacted marine coastal zone where the Pseudomonas isolates from the study were completely susceptible to colistin sulphate and only one of the 146 isolates was resistant to piperacillin [24]. In a study carried out on clinical isolates in Jamaica, the reported Pseudomonas species resistance was 17.6\% (piperacillin), 19.6\% (ceftazidime) and 9.8\% (imipenem and meropenem) [25]. This was not in agreement with the result of this present study that showed the isolates being completely resistant to imipenem and meropenem while a higher resistance was observed for ceftazidime and piperacillin.

The occurrence of Enterobacteria especially $E$. coli in wastewater has been extensively reported by several authors. Danishta et al. [26], Amaya et al. [27] and Galvin et al. [28] all reported the occurrence of E. coli in wastewater obtained from environmental, hospital and other sources in various parts of the globe. The occurrence of E. coli in this study confirmed their reports that Escherichia coli and other bacterial strains are frequently encountered in wastewater samples.

The occurrence of high level of resistance to antibiotics by E. coli has also been well documented; Alhaj et al. [29] reported that anthropogenic activities have contributed significantly to the spread of antibiotic resistance in the environment. They were of the view that antibiotic resistant $E$. coli can enter the environment via sewage and every other form of faecal contamination. This cannot be ruled out, however, because of the widespread use of antibiotics in animal husbandry; which has led to increased resistance in most environmental isolates. 
Table 1. Phenotype of resistance of the Pseudomonas strains to the selected antibiotics.

\begin{tabular}{ccc}
\hline Phenotype of resistance & Number of isolates showing trait & Percentage number of isolates (\%) \\
\hline${ }^{1} \mathrm{CAZ},{ }^{2} \mathrm{PRL}$ & 60 & 100 \\
\hline
\end{tabular}

Footnote: ${ }^{1}$ ceftazidime, ${ }^{2}$ piperacillin.

Table 2. Phenotype of resistance of the Escherichia coli strains to the selected antibiotics.

\begin{tabular}{ccc}
\hline Phenotype of resistance & Number of isolates showing resistance & Percentage number of isolates (\%) \\
\hline${ }^{2} \mathrm{CAZ}, \mathrm{FOX}$ & 1 & 1 \\
${ }^{2} \mathrm{CAZ},{ }^{5} \mathrm{OX}$ & 14 & 1 \\
${ }^{1} \mathrm{ATM},{ }^{2} \mathrm{CAZ},{ }^{4} \mathrm{FOX}$ & 1 & 2 \\
${ }^{1} \mathrm{ATM},{ }^{2} \mathrm{CAZ},{ }^{5} \mathrm{OX}$ & 2 & 14 \\
${ }^{2} \mathrm{CAZ},{ }^{4} \mathrm{FOX},{ }^{5} \mathrm{OX}$ & 14 & 30 \\
${ }^{2} \mathrm{CAZ},{ }^{6} \mathrm{TE},{ }^{5} \mathrm{OX}$ & 30 & 2 \\
${ }^{2} \mathrm{CAZ},{ }^{3} \mathrm{ETP},{ }^{5} \mathrm{OX}$ & 2 & 1 \\
${ }^{1} \mathrm{ATM},{ }^{2} \mathrm{CAZ},{ }^{3} \mathrm{ETP}, \mathrm{FOX}$ & 1 & 2 \\
${ }^{1} \mathrm{ATM},{ }^{2} \mathrm{CAZ},{ }^{4} \mathrm{FOX},{ }^{5} \mathrm{OX}$ & 1 & 1 \\
${ }^{1} \mathrm{ATM},{ }^{2} \mathrm{CAZ},{ }^{3} \mathrm{ETP},{ }^{5} \mathrm{OX}$ & 2 & 1 \\
${ }^{1} \mathrm{ATM},{ }^{2} \mathrm{CAZ},{ }^{3} \mathrm{ETP},{ }^{6} \mathrm{TE}$ & 1 & 2 \\
${ }^{2} \mathrm{CAZ},{ }^{3} \mathrm{ETP},{ }^{4} \mathrm{FOX},{ }^{5} \mathrm{OX}$ & 1 & 1 \\
${ }^{2} \mathrm{CAZ},{ }^{3} \mathrm{ETP},{ }^{6} \mathrm{TE},{ }^{5} \mathrm{OX}$ & 2 & 1 \\
${ }^{2} \mathrm{CAZ},{ }^{6} \mathrm{TE},{ }^{4} \mathrm{FOX},{ }^{5} \mathrm{OX}$ & 24 & 1 \\
${ }^{1} \mathrm{ATM},{ }^{2} \mathrm{CAZ},{ }^{3} \mathrm{ETP},{ }^{6} \mathrm{TE},{ }^{5} \mathrm{OX}$ & 2 & 1 \\
${ }^{1} \mathrm{ATM},{ }^{2} \mathrm{CAZ},{ }^{3} \mathrm{ETP},{ }^{4} \mathrm{FOX},{ }^{5} \mathrm{OX}$ & 1 & 1 \\
${ }^{1} \mathrm{ATM},{ }^{2} \mathrm{CAZ},{ }^{6} \mathrm{TE},{ }^{4} \mathrm{FOX},{ }^{5} \mathrm{OX}$ & $\mathbf{1 0 0}$ & 2 \\
\hline $\mathrm{Total}$ & 1 & 1 \\
\hline
\end{tabular}

Footnote: ${ }^{1}$ aztreonam; ${ }^{2}$ ceftazidime; ${ }^{3}$ ertapenem; ${ }^{4}$ cefoxitin; ${ }^{5}$ oxacillin; ${ }^{6}$ tetracycline.

From the study of Galvin et al. [28], there was a percentage resistance of $14 \%$ to ceftazidime of the $254 \mathrm{E}$. co$l i$ isolated in their study and this is not in agreement with the present study where $100 \%$ resistance was observed to the same antibiotic. Similarly, there was no agreement in the resistance of the E. coli from both studies to cefoxitin, as $15 \%$ of the total isolates from the former showed resistance as against $43 \%$ observed in the present study.

The result of this study showed that $58 \%$ of the $E$. coli isolates were resistant to tetracycline and this value is higher than the $20 \%$ reported in a similar study conducted in Lagos a neighboring state by Akano et al. [1]. Furthermore, $18 \%$ resistance to tetracycline was also reported in a recent study by Farmer et al. [30] which is lower compared to the value observed in this present study. The disparity in the values might be attributed to the differences in the nature of the samples, while this present study was carried out on abattoir effluents, the other study was on fresh water samples. The observation from the present study revealed that $59.7 \%$ of the $E$. coli strains were resistant to ceftazidime which is also in agreement with the over $50 \%$ resistance recently reported for $E$. coli to the same antibiotic in a study carried out in a municipal dumpsite in Tanzania [31].

\section{Conclusion}

The findings of this study showed that the Pseudomonas strains did not exhibit multi-resistance to the tested antibiotics which was an indication that the risk of spreading Pseudomonas strains that could be multi-resistant seems very low. However, the multi-resistance exhibited by the E. coli strains underscores the need to closely monitor multidrug resistant pathogens in the effluents before discharge into the environment and the need to en- 
force treatment of the effluents before disposal.

\section{Acknowledgements}

The authors would wish to acknowledge Dauda Ajibola and Chidinma Nzekwe for their inputs. They are also very grateful to the Environmental Microbiology and Biotechnology unit for their supports.

\section{References}

[1] Akano, S.O., Moro, D.D., Deji-Agboola, A.M. and Oluwadun, A. (2013) Public Health Implication of Listeria Species and Other Bacteria Isolates of Abattoir Effluents in Lagos, Nigeria. International Research Journal of Microbiology, 4, 162-167.

[2] Adeyemo, I.G. and Adeyemo, O.K. (2007) Waste Management Practices at the Bodija Abattoir, Nigeria. International Journal of Environmental Studies, 64, 71-82. http://dx.doi.org/10.1080/00207230601124989

[3] Pelczar, M.J., Chan, E.C.S. and Kreig, N.R. (2002) Microbiology. 5th Edition, Tata McGraw-Hill, New Delhi.

[4] Narfanda, W.D., Yaji, H. and Icubkomawa, H.I. (2005) Impact of Abattoir Waste on Aquatic Life. Global Journal of Pure and Applied Science, 12, 31-33.

[5] Madgan, M.T., Martinko, J.M. and Parker, J. (1997) Biology of Microorganism. 5th Edition, Prentice Hall, New York.

[6] Black, R.E., Levine, M., Clement, M.L., Hughes, T.P. and Blasser, M.J. (1998) Experimental Campylobacter jejuni Infection in Humans. Journal of Infectious Disease, 157, 472-479. http://dx.doi.org/10.1093/infdis/157.3.472

[7] Adesemoye, A.O., Opere, B.O. and Makinde, S.O. (2006) Microbial Content of Abattoir Wastewater and Its Contaminated Soil in Lagos, Nigeria. African Journal of Biotechnology, 8, 1963-1968.

[8] Nwanchukwu, M.I., Akinde, S.B., Udujih, O.S. and Nwachuckwu, I.O. (2011) Effect of Abattoir Waste on the Population of Proteolytic and Lipolytic Bacteria in a Receipient Water Body (Otamiri River). Global Research Journal of Science, 1, 40-42.

[9] Akpan, A.W. (2004) The Water Quality of Some Tropical Freshwater Bodies in Uyo (Nigeria) Receiving Municipal Effluents, Slaughter-House Washings and Agricultural and Drainage. The Environmentalist, 24, 49-55. http://dx.doi.org/10.1023/B:ENVR.0000046346.93401.5c

[10] Wenzel, R.P. and Edmond, M.B. (2009) Managing Antibiotic Resistance. Journal of Medicine, 343, 1961-1963.

[11] Sayah, R.S., Kaneene, J.B., Johnson, Y. and Miller, R.A. (2005) Patterns of Antimicrobial Resistance Observed in Escherichia coli Isolates Obtained from Domestic- and Wild-Animal Fecal Samples, Human Septage, and Surface Water. Applied Environmental Microbiology, 71, 1394-1404. http://dx.doi.org/10.1128/AEM.71.3.1394-1404.2005

[12] Kelly, M.P., Pericles, D., Julio, D.S. and Alexeia, B. (2013) Antimicrobial Susceptibility Profile of Pseudomonas Spp. Isolated from a Swine Slaugherhouse in Dourados, Mato Grosso do Sul State, Brazil. Revista Argentina de Microbiologia, 45, 57-60.

[13] Berquo, L., Barros, K., Lima, R. and Bertoichi, A.U. (2004) Antimicrobianos enuma populacao urbana. Revista de Saúde Pública, 36, 239-243. http://dx.doi.org/10.1590/S0034-89102004000200013

[14] APHA (1998) Standard Methods for the Examination of Water and Wastewater. 20th Edition, American Public Health Association, Washington DC, 412.

[15] Berger, P.S. and Oshiro, R.K. (2002) Source Water Protection: Microbiology of Source Water. In: Bitton, G., Ed., Encyclopedia of Environmental Microbiology, Wiley-Interscience, New York, 2967-2978.

[16] Adekanmbi, A.O. and Falodun, O.I. (2015) Heavy Metals and Antibiotics Susceptibility Profiles of Staphylococcus aureus Isolated from Several Points Receiving Daily Input from the Bodija Abattoir in Ibadan, Oyo State, Nigeria. Advances in Microbiology, 5, 871-880. http://dx.doi.org/10.4236/aim.2015.513091

[17] Harrigan, W.F. and McCance, M.E. (1976) Laboratory Methods in Food and Dairy Microbiology. Academic Press Incorporated, London.

[18] Sneath, P.H.A. (1996) Bergey's Manual of Determinative Bacteriology. William and Wilkins, Baltimore.

[19] Clinical and Laboratory Standards Institute (2014) Performance Standards for Antimicrobial Susceptibility Testing. The 24th Informational Supplement, January 2014.

[20] Igbinosa, E.O., Odjadjare, E.E., Igbinosa, I.H., Orhue, P.O., Omoigberale, M.N.O. and Napoleon, A. (2012) Antibiotic Synergy Interaction against Multidrug-Resistant Pseudomonas aeruginosa Isolated from an Abattoir Effluent Environment. The Scientific World Journal, 12, Article ID: 308034.

[21] Atuanya E.I., Nwogu, N.A. and Akpor, E.A. (2012) Effluent Qualities of Government and Private Abattoirs and Their Effects on Ikpoba River, Benin City, Edo State, Nigeria. Advances in Biological Research, 6, 196-201. 
[22] Neboh, H.A., Ilusanya, O.A., Ezekoye, C.C. and Orji, F.A. (2013) Assessment of Ijebu-Igbo Abattoir Effluent and Its Impact on the Ecology of the Receiving Soil and River. Journal of Environmental Science, Toxicology and Food Technology, 7, 61-67.

[23] Sivaraj, S., Murugesan, P., Muthuvelu, S., Purusothaman, S. and Silambarasan, A. (2011) Comparative Study of Pseudomonas aeruginosa Isolate Recovered from Clinical and Environmental Samples against Antibiotics. International Journal of Pharmacy \& Pharmaceutical Science, 4, 103-110.

[24] Luczkiewicz, A., Kotlarska, E., Artichowicz1, W., Tarasewicz, K. and Fudala-Ksiazek, S. (2015) Antimicrobial Resistance of Pseudomonas Spp. Isolated from Wastewater and Wastewater-Impacted Marine Coastal Zone. Environmental Science and Pollution Research, 22, 19823-19834. http://dx.doi.org/10.1007/s11356-015-5098-y

[25] Brown, P.D. and Izundu, A. (2004) Antibiotic Resistance in Clinical Isolates of Pseudomonas aeruginosa in Jamaica. Revista Panamericana de Salud Pública, 16, 125-130. http://dx.doi.org/10.1590/S1020-49892004000800008

[26] Danishta, I., Ismet, M., Sonatun, D. and Jaufeerally-Fakim, Y. (2010) Antibiotic Resistance of Escherichia coli Isolates from Environmental and Waste Water Samples in Mauritius. Advances in Environmental Biology, 4, 1-9.

[27] Amaya, E., Reyes, D., Paniagua, M., Calderon, S., Rashid, M.U., Colque, P., Kuhn, I., Mollby, R., Weintraub, A. and Nord, C.E. (2012) Antibiotic Resistance Patterns of Escherichia coli Isolates from Different Aquatic Environmental Sources in Leon, Nicaragua. Clinical Microbiology Infections, 18, 347-354. http://dx.doi.org/10.1111/j.1469-0691.2012.03930.x

[28] Galvin, S., Boyle, F., Hickey, P., Vellinga, A., Morris, D. and Cormican, M. (2010) Enumeration and Characterization of Antimicrobial-Resistant Escherichia coli Bacteria in Effluent from Municipal, Hospital, and Secondary Treatment Facility Sources. Applied and Environmental Microbiology, 76, 4772-4779. http://dx.doi.org/10.1128/AEM.02898-09

[29] Alhaj, N., Mariana, N.S., Raha, A.R. and Ishak, Z. (2007) Prevalence of Antibiotic Resistance among Escherichia coli from Different Sources in Malaysia. International Journal of Poultry Science, 6, 293-297. http://dx.doi.org/10.3923/ijps.2007.293.297

[30] Farmer, K., James, A., Naraine, R., Dolphin, G., Sylvester, W., Amadi, V. and Kotelnikova, S.V. (2016) Urinary Tract Infection Escherichia coli Is Related to the Environmental Escherichia coli in their DNA Barcoding and Antibiotic Resistance Patterns in Grenada. Advances in Microbiology, 6, 33-46. http://dx.doi.org/10.4236/aim.2016.61004

[31] Mwaikono, K.S., Maina, S. and Gwakisa, P. (2015) Prevalence and Antimicrobial Resistance Phenotype of Enteric Bacteria from a Municipal Dumpsite. Journal of Applied \& Environmental Microbiology, 3, 82-94. 